\title{
REMOVAL OF OXYTETRACYCLINE BY POLYMERS. AN OVERVIEW
}

\author{
BERNABÉ L. RIVAS * PABLO ONATE AND DANIEL A. PALACIO \\ Polymer Department, Faculty of Chemistry, University of Concepcion, Concepcion.
}

\begin{abstract}

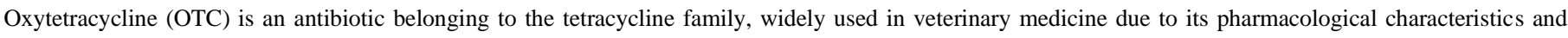
adequate cost/effectiveness ratio.

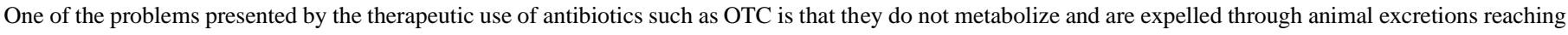
the effluent of wastewater, rivers, and lagoons, causing accumulation and generating resistance to certain pathogens, mainly zoonotic bacteria.

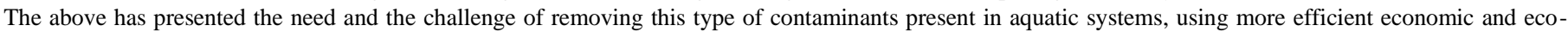
friendly methods than the conventional ones already known. A promising alternative is removal by using polymeric materials.

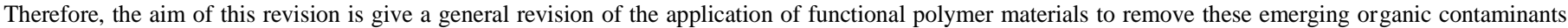
OTC.
\end{abstract}

Keywords: Antibiotics, Polymers, Oxytetracycline, Environment, Removal.

\section{INTRODUCTION}

Since historical records exist man has tried to mitigate ailments and diseases, trying to prolong his life, using mineral and plant animal resources, which until the mid-20th century were considered therapeutic resources par excellence. Despite scientific advances in the field of medicine, it gave rise to the development of new therapeutic tools ${ }^{1}$. One of the greatest achievements in current medicine for the control of most infectious diseases was the development of antibiotics, drugs that are classified according to their chemical structure, type of action or spectrum of activity ${ }^{2}$,sulfonamides being one of the first tools for clinical use in the $1930 \mathrm{~s}^{3}$

Between 2000 and 2008 Chile experienced growth in the export of salmon and trout, becoming the second largest exporter in the world ${ }^{4}$.As a result of this intensive production in salmon farming ${ }^{5}$, quinolone and tetracyclines were the main families of antibiotics used as antibacterial agents. The large use of these compounds in different areas of daily life has consequently generated an alarming amount of waste that reaches the aqueous ecosystem generating interest in the impact that these can cause ${ }^{6}$.

Due to the indiscriminate use of antibiotics in recent years the presence of antibiotics in aquatic systems is one of the global concerns because it threatens water resources ${ }^{7}$ and bacteria with antibiotic-resistant genes pose a great risk to the environment as in human health ${ }^{8}$. From the problem posed by the indiscriminate use of antibiotics different methods of addressing this problem are presented such as: advanced oxidation ${ }^{9}$, membrane processes such as reverse osmosis, ultrafiltration, nano filtration ${ }^{10,11}$, adsorption ${ }^{12}$, biological processes ${ }^{13}$, advancedoxidation ${ }^{14}$, where functional polymeric materials are highly developed due to the large applications present at the pharmaceutical, environmental among other fields and especially as adsorbents ${ }^{15}$. In this sense, adsorption processes are an easy-to-use method, low costs at the level of energy requirements and selective to certain molecules of interest ${ }^{16}$.

As mentioned above, the objective of this review is to show in a general way the environmental problems present by antibiotics, in particular highly used oxytetracycline, OTC, in both veterinary and human medicine and the role that polymeric materials play in minimizing the impacts caused by this type of contaminants.

\section{Synthesis and properties of Oxytetracycline.}

\subsection{Synthesis and uses of Oxytetracycline.}

In the search for new and more powerful drugs that can fight diseases and infections, tetracyclines have become one of the molecules of interest, considered one of the families of broad-spectrum antibiotics. Oxytetracycline is a first-generation antimicrobial, discovered by Finlay et al. in the late $1950 \mathrm{~s}^{17}$ in the search for a therapeutic agent capable of dealing with rickettsia bacteria, spirochetas and certain viruses and protozoan organisms ${ }^{18}$. The first tetracyclines were obtained from soil samples from many locations on different continents ${ }^{19}$, after isolating the bacterium Streptomyces Aureofasciens from the samples, chlortetracycline was fermented, followed by the isolation of the S. Rimosus microorganism from which the second member of the tetracycline family was obtained ${ }^{20}$. Figure 1 shows the biosynthesis of the first tetracyclines.

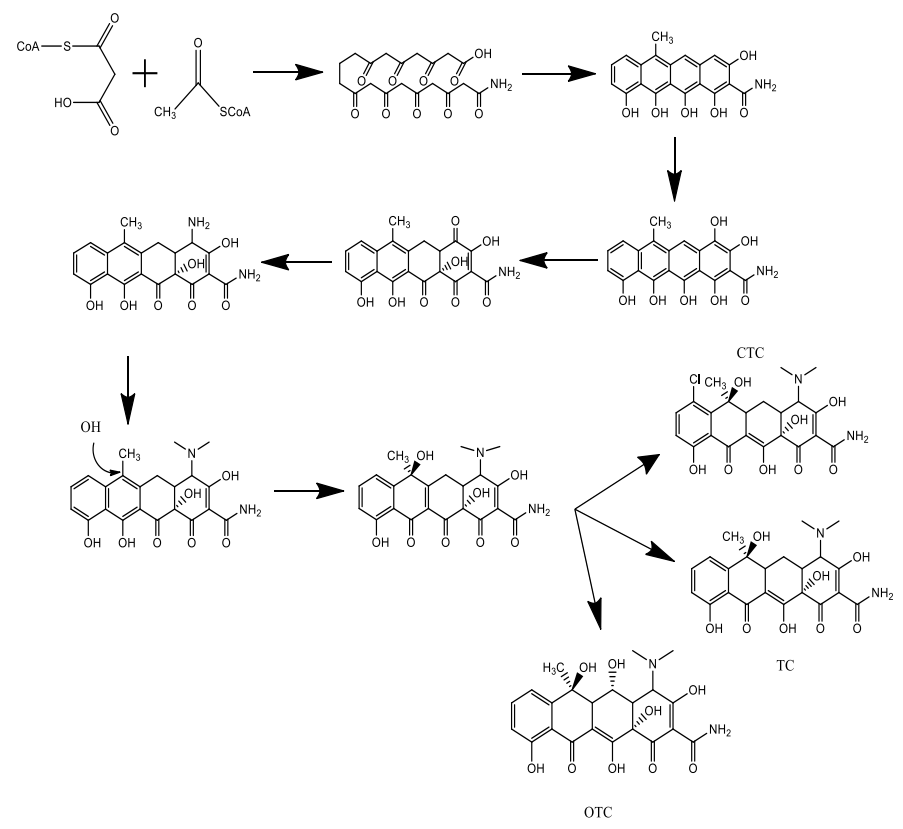

Figure 1. Biosynthesis of the OTC, CTC, and TC antibiotics from Streptomyces species. Adapted image of Nelson et al. ${ }^{21}$

Tetracyclines have a bacteriostatic action against pathogenic microorganisms inhibiting their protein synthesis at the ribosomal level thus decreasing bacterial infectious diseases and related mortality. The advantages of these antibiotics over penicillin is that they have a greater spectrum of action, especially Gram-negative bacteria, in addition to lower toxicity which translates as a higher tolerance on the part of the individual to treat ${ }^{22}$. For these reasons oxytetracycline is used in human medicine for the treatment of zoonotic diseases, inflammatory pelvic, spirochete infections, "Lyme' disease, among others ${ }^{23}$. It is currently mainly used in veterinary medicine as a stimulant for the growth of farm animals, in the treatment of infections of farmed fish and breeding birds ${ }^{24}$, among others. 


\subsection{Physico-chemical properties of Oxytetracycline.}

Oxytetracycline is presented as a crystalline yellow powder, odorless, moderately hygroscopic, slightly bitter and stable in solid state. But when exposed to sunlight or wet air darkens ${ }^{25}$. It is an amphoteric specie that can form sodium salts or water-soluble hydrochloride, is stable for three or four days in neutral solution, little soluble in acid solution and very unstable in alkaline $\mathrm{pH}$ due to its speciation ${ }^{26}$. Other research shows that acidic conditions promote stability while alkaline conditions promote their degradation ${ }^{27}$.

The tetracycline family is characterized by a basic skeleton of perhydronaphtacene and its nomenclature derived from substitutions in the ring, in addition its linear tetracyclic structure provides them with a great antibacterial and pharmacokinetic activity which are also influenced by the processing of metal ions ${ }^{28}$.

The chemical formula of oxytetracycline is $\mathrm{C}_{22} \mathrm{H}_{24} \mathrm{~N}_{2} \mathrm{O}_{9}$, the name according to the International Union of Pure and Applied Chemistry, IUPAC. (4S,4aR,5S,5aR,6S,12aS)-4-(dimethylammonium) 3,5,6,10,11, hexahydroxy-6methyl-1,12-dioxo-1,4,4a,5,5a,6,12,12a-octahydrotetraceno-2-carboxamida. The chemical structure is shown in Figure 2.

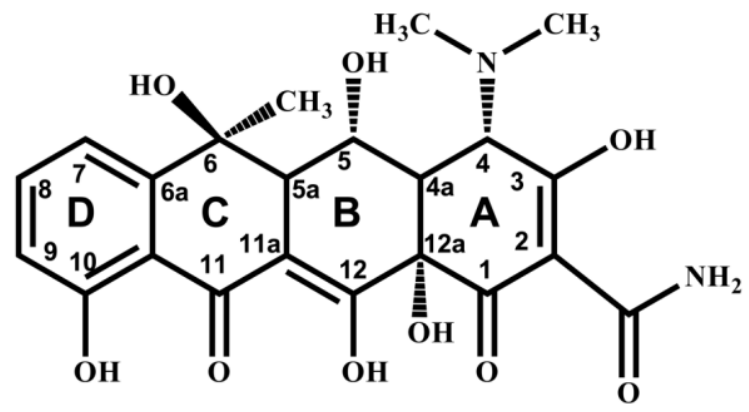

Figure 2. Chemical structure of the OTC. Adapted image from doctoral thesis by Mateos, A.D. ${ }^{29}$

The detection of such molecules in aqueous systems is conventionally performed by high-resolution liquid chromatography (HPLC), with UV-VIS detector. However, an easy and less expensive method in UV-VIS spectroscopy determination. In Figure 3 is shown the absorption spectrum of oxytetracycline which has an absorption maximum at approximately $270 \mathrm{~nm}$, attributed to the absorption of chromophore formed by the amide, diketone, and hydroxyl groups of the molecule's A-ring. On the other hand, the maximum approximately at 350 $\mathrm{nm}$ is due to the absorption of chromophore BCD (see Figure 2) which is made up of the phenyl hydroxytone group found in the carbonyl and ketone groups in the corresponding $\mathrm{D}, \mathrm{C}$, and $\mathrm{B}$ rings. Both absorption maximums are characteristic of this family of antibiotics ${ }^{21}$.

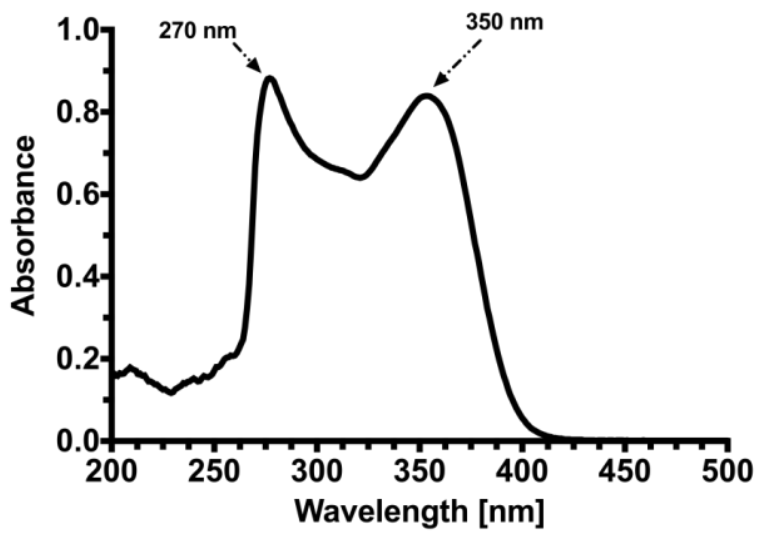

Figure 3. Molecular absorption spectrum of OTC.

Tetracyclines have three functional groups of dimethylamine, diketone and tricarbonyl that contribute to their dissociation with pKa values close to 3.27 for $\mathrm{pKa}_{1}, 7.32$ for $\mathrm{pKa}_{2}$ and 9.11 for $\mathrm{pKa}_{3}^{30,31,32}$

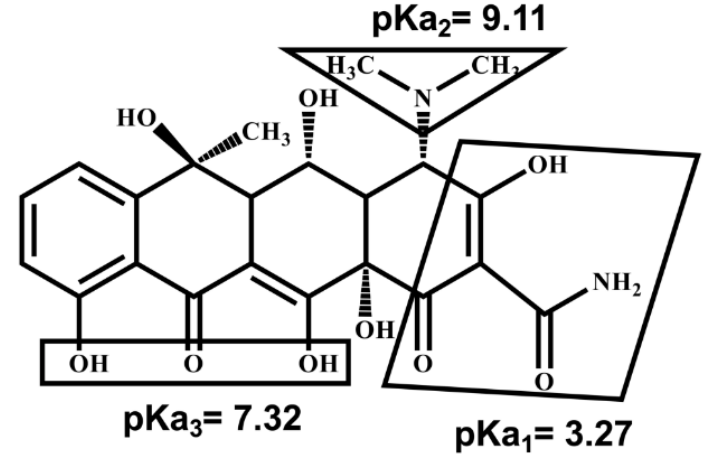

Figure 4. Dissociation constants of OTC. Image adapted from Aaryn et al. ${ }^{33}$

\section{Oxytetracycline as a contaminant in aqueous systems}

To meet the growing demand for animal food that has been generated in recent decades due to the constant growth of the human population has become vitally important to intensify animal production systems, which consequently has produced a higher demand for different drugs for the fight of various diseases, among these therapeutic tools are antimicrobials such as tetracyclines ${ }^{5,34,35}$.

Oxytetracycline is widely used as a food additive for the treatment of infections in cultured fish, prophylactic of bacterial diseases in plants and mainly as a livestock growth stimulant ${ }^{36}$. In general, tetracyclines are the most widely used antibiotics in pigs worldwide, according to the Veterinary Medicines Directorate (VMD) of 387 tons of antibiotics used in $2007,45 \%$ were tetracyclines ${ }^{37}$.

Mostly tetracyclines are administered orally and are incompletely absorbed, in the case of oxytetracycline their absorption is $50 \%$, being widely distributed in body tissues and fluids.

The problem is that oxytetracycline does not undergo metabolization like the rest of the first generation of the family (with the exception of tetracycline) which means that it is mostly eliminated by renal excretion by glomerular filtration ${ }^{38}$.

Because renal excretion is the main source of tetracycline elimination and its high recovery rate in it has been detected thanks to analytical techniques such as liquid chromatography combined with mass spectrometry (LC/MS), in surface water effluents and wastewater treatment stations where they are not completely eliminated. According to a study by the United States Geological Survey, perceptible levels were determined in several US Rivers, at concentration levels of $0.10 \mathrm{~g} \mathrm{~L}^{-139}$.

Long-term exposure of antibiotics in ecosystems has become a concern in recent years as they generate resistance to certain pathogens, mainly zoonotic bacteria $^{23}$. To avoid this problem of environmental pollution and that these molecules reach aquatic systems, different methods of removal and elimination have been reported in the literature as are conventional methods ${ }^{40}$, coagulation removal, and activated carbons, ion exchange resins and the use of functional soluble polymers coupled to ultrafiltration membranes (LPR) ${ }^{11,40,41}$. Below is presented an overview of methods to remove antibiotics, where functional polymers have been used in tetracycline removal.

\section{Polymers used in the removal of Oxytetracycline.}

Polymers play an important role in the process of minimizing the impact of these types of pollutants to the environment. Currently, there are a variety of methods for removing a contaminant in water ${ }^{12,42,43}$. The adsorption process is one of the most effective and simple method to remove contaminants, and polymeric adsorbents are a potential alternative with reference to other types of adsorbents most commonly used for the removal of contaminants ${ }^{44}$. In general, polymeric adsorbents can effectively remove many of the organic pollutants, metal ions, phenolic compounds, organic acids, aromatic and polyaromatic hydrocarbons, alkanes and their derivatives ${ }^{45-46}$. One of the important factors in the removal of emerging antibiotic-type contaminants is to understand the removal mechanisms that occur in the interaction processes present between the functional groups of the polymer and the antibiotic. Within these interactions are: electrostatic interactions, hydrogen bonds, dipole-dipole, hydrophobic interactions, and $\pi-\pi$ interactions ${ }^{47-48}$ (see figure 5). 


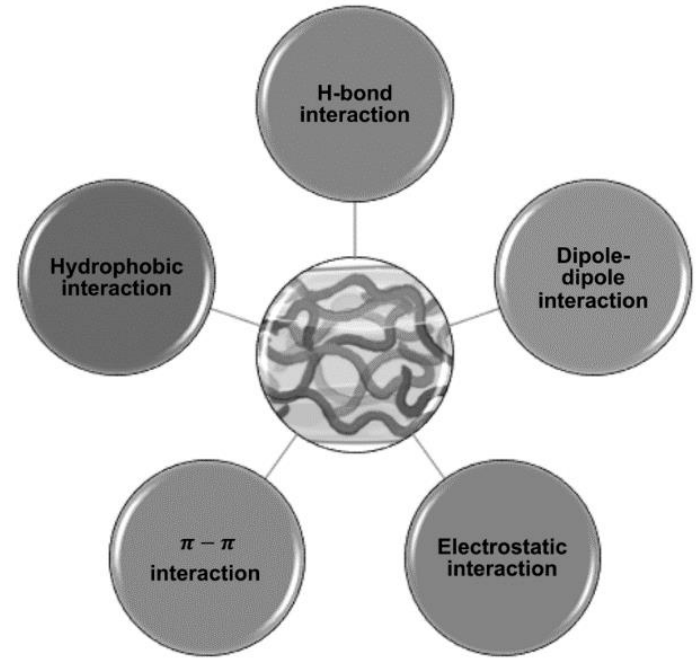

Figure 5. Mechanism of interaction in the processes of removal of antibiotics by polymers. Adapted image of Burbano et al. ${ }^{15}$.

\subsection{Removal with ion exchange resins.}

Ion exchange resins (IER) have been used in many methods of purification, water treatments and chemical analysis, both industrially and in laboratories, which together with its wide variety of resin types, offers an efficient solution for different types of scientific problems in the chemical and pharmaceutical ${ }^{49}$.

Resins are crosslinked water-insoluble polymers that contain repetitive ionized groups along their chain, which are neutralized by a counterion that can be exchanged symmetrically when they come into contact with other ions of the same Most drug residues present in water are in ionic form, for this reason a treatment with ion exchange resins can be considered an effective and attractive method. These characteristics allow them to be used also as matrix for controlled drug release $\mathrm{e}^{49,50}$.

Choi et al., studied a solid phase extraction treatment connected to highresolution liquid chromatography combined with a selective mass detector, in order to model the actual concentrations in wastewater, obtaining removal percentage in the range $74.3 \%$ and $100 \%$ tetracycline and sulfonamide ${ }^{51}$. In addition, they evaluated the effect of the interference of organic matter, for this he performed antibiotic solutions with deionized water and in water with dissolved organic carbon (DOC), under conditions of $\mathrm{pH} 7.0$ and $25^{\circ} \mathrm{C}$. According to Figure 6 the treatment with ion exchange resins in the removal of tetracyclines turned out to be effective in deionized water, obtaining an elimination percentage of $80 \%$ oxytetracycline. On the other hand, the removal of tetracyclines was disadvantaged in the presence of organic matter, due to competition between organic matter and antibiotic ${ }^{52}$.

\section{OTC}

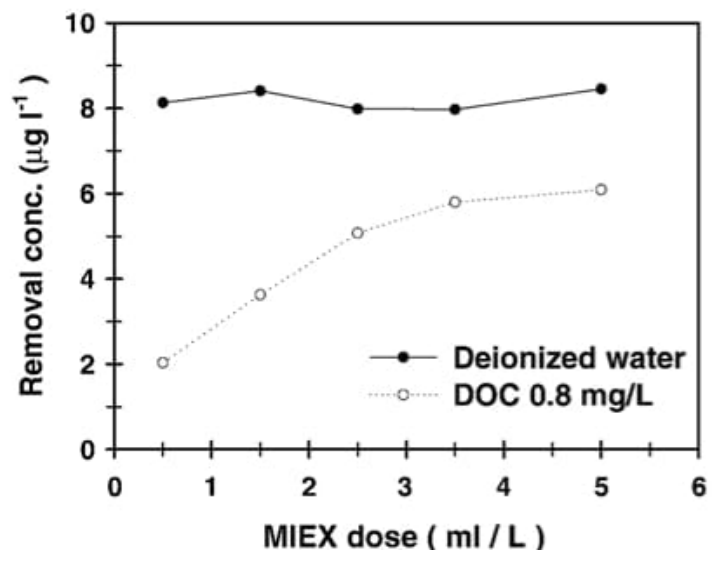

Figure 6. Removal of oxytetracycline in deionized water and organic matter with MIEX resin. Image of Choi et al. ${ }^{52}$
Wang et al. removed tetracycline using a commercial ion exchange resin provided by Orica Watercare (Melbourne, Australia), comparing it with activated carbon powder. The results obtained in the adsorption capacity of tetracycline were $443.2 \mathrm{mg} \mathrm{L}^{-1}$ at $25^{\circ} \mathrm{C}$. These found results show that the resin has higher adsorption capability and tested adsorption rates when compared to activated carbon powder. On the other hand, the $\mathrm{pH}$ of the solutions has a strong impact on adsorption processes and the largest tetracycline removal was obtained at neutral $\mathrm{pH}^{53}$.

Yang et al. used porous synthetic resins and evaluated the interaction and adsorption of tetracycline in aqueous solutions. For the study MN-200 and NDA150 hypercrosslinked resins and $\mathrm{MN}-150$ polystyrene amino resins were selected. The results found in this study were that although the resins have different properties and different pore structures, similar patterns were observed in adsorption processes to different pHs. They also demonstrated that the elimination effects were influenced by the formation of hydrogen bonds, hydrophobic effects, and $\pi-\pi$ interactions between the donor and the electron acceptor and hydrophobic effects ${ }^{54}$.

\subsection{Water-soluble functional polymers: LPR technique.}

The liquid-phase polymer-based retention, LPR technique is an easy separation technique that is used to separate species with molecular weights lower than those used by the polymer. This technique is coupled to ultrafiltration membranes that are usually regenerated cellulose with a molar mass cut off, MMCO, varying between 5 and $10 \mathrm{kDa}^{55-61}$. This technique has been also widely used in the removal or separation of inorganic low molecular weight contaminants, like metal ions in aqueous solutions such as arsenic, chromium, molybdate ${ }^{56}$, mercury, among other metal ions. However, there are few studies reporting use in applications in the removal of organic pollutants, especially emerging pharmaceutical pollutants such as antibiotics ${ }^{57}$.

Palacio et al. used functional water-soluble polymers in the elimination of tetracycline, synthesizing three copolymers with different load ratios and monomers containing sulfonic acid and quaternary ammonium groups. The copolymerization reaction was carried out by radical polymerization. All the copolymers were characterized by FTIR and NMR spectroscopy. It was determined that the copolymers showed a tendency to the alternate. Different studies were performed in tetracycline removal such as $\mathrm{pH}$, ion strength, concentration polymer variation, and determination of maximum retention capacity. The functional copolymers have a high antibiotic removal capacity with percentages greater than $70 \%$ and a maximum retention capacity ranging from 214.8 to $732.2 \mathrm{mg}$ tetracycline/ g copolymer ${ }^{58}$. Figure 7 shows the copolymers used for the tetracycline removal by LPR technique.
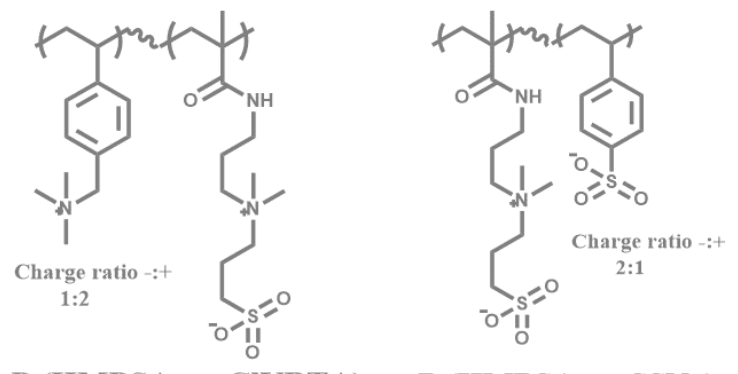

P (HMPSA-co-CIVBTA) P (HMPSA-co-SSNa)<smiles>CCC(CCCCC(C)C)C(=O)NCCCN(C)C</smiles>

P (CIAPTA-co-SSNa)

Figure 7. Water-soluble copolymer studied in the removal of oxytetracycline using the LPR technique. Adapted image of Palacio et al ${ }^{58}$. 
On the other hand, Palacio et al. also evaluated the removal of tetracycline by using alkylated chitosan with groups of quaternary ammonium, obtaining removal percentages greater than $80 \%$ and maximum retention capacities of $632.8 \mathrm{mg} \mathrm{g}^{-1} 47$. It shows the structure of the polymers used in the removal of tetracycline, showing that the retention mechanism of the polymer is mostly due to electrostatic interactions due to the quaternary ammonium groups of the polymer and the functional groups of the negatively charged antibiotic due to the speciation present at $\mathrm{pH} 11$. However, hydrogen bridge interactions also play an important role in the process of removing this antibiotic ${ }^{47}$. Figure 8 shows the mechanism proposed for the interaction between the water-soluble polymer and the antibiotic.

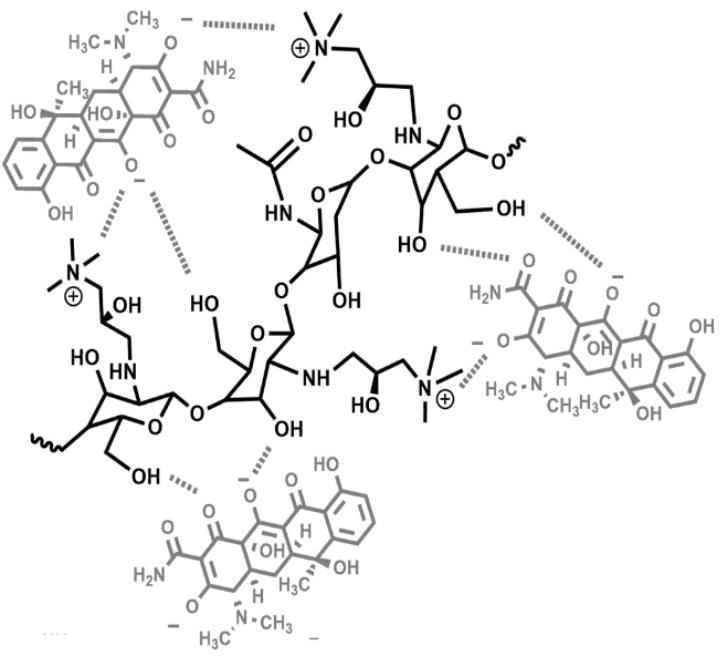

Figure 8. Mechanism proposed by Palacio et al. in the removal of tetracycline using modified chitosan with quaternary ammonium groups ${ }^{47}$.

\subsection{Imprinting molecular polymers}

Rodríguez-Dorado et al. used molecularly imprinted polymers for the recovery and elimination of oxytetracycline in aqueous systems, by using computational designs. The polymers used in this study were 2-hydroxyethyl methacrylate (AMPS) and 2-acrylamide-2-methylpropane sulfonic acid both chosen according to oxytetracycline affinity. These monomers were evaluated as molecularly printed and unprinted polymer materials obtained from AMPS showed greater affinity with oxytetracycline, where absorption capacity depended on ionic strengtht ${ }^{62}$.

$\mathrm{Lu}$ et al. prepared molecularly printed polymers for selective removal and removal of traces of tetracycline residues by solid phase microextraction. Methacrylic acid (MA) and 2-hydroxyethyl methacrylate (HEMA) were used as bifunctional monomers to improve adsorption performance in microextraction processes. The results obtained in this research show percentages of oxytetracycline recovery from 77.3 to $100 \%$, demonstrating that the molecular imprint polymers obtained in this study can be successfully used in determining waste breeds of this contaminant ${ }^{63}$.

Aguilar et al. prepared molecularly printed polymers for use in the selective elimination of oxytetracycline. This work consisted in the synthesis and characterization of materials and their application. The polymers were obtained by precipitation polymerization using tetracycline as a mold molecule, methacrylic acid as functional monomer and ethylene glycol dimethacrylate as a crosslinking reagent and ammonium persulfate as initiator. The percentage of removal obtained was $95.4 \%$ under conditions of $1.0 \mathrm{~mL}$ sample, $20 \mathrm{mg}$ adsorbent and $\mathrm{pH} 6.0$ for a contact period of $15 \mathrm{~min}$. The researchers concluded that this type of material provides selective and efficient development in the elimination of this type of organic emergent contaminants ${ }^{64}$.

\section{CONCLUSIONS}

This review presents an overview of the removing studies of emerging antibiotic contaminants such as Oxytetracycline through the use of polymers. Oxytetracycline is known to be a first-generation antibiotic in the tetracycline family, a drug widely used in veterinary medicine primarily as a stimulant for the growth of farm animals and treatment of infections in culture fish. As a result of the intensification of animal production systems, the use of this type of drugs has been increased, causing accumulation of their residues in farmland, surface water effluents and wastewater treatment stations. Conventional treatments of these flats are not as effective as eliminating these types of contaminants. So polymeric materials and their derivatives have been used as an alternative for the removal of contaminants in water. However, there is a need to be able to obtain materials with greater selectivity to certain contaminants of interest, and work to obtain greater elution and reusability of the polymer. Finally, the polymers play an important role in the processes of removal of emerging contaminants of the type antibiotic, since it can be played with the creations of custom functional groups in order to minimize the environmental impact. As well, in the construction of new materials from renewable natural sources that are bio-degradable and contribute to the development and improvement of the environment.

\section{ACKNOWLEDGEMENTS}

The authors thank the financial support of FONDECYT (Grant No 1190469).

\section{REFERENCES}

1. Cruz-Coke Madrid, R. Historia de la Medicina Chilena; Andres Bello: Santiago, Chile 1995.

2. Brugueras, M. C.; García, M. M. Rev. Cuba. Med. Gen. Integr.1998, 14, $347-$ 361.

3. Morris, A.; Kellner, J. D.; Low, D. E. Curr. Opin. Microbiol. 1998, 1, 524 529.

4. Doren, D.; Gabella, J. P. Terram. F. 2001, 1, 39.

5. Gesche, E.; Madrid, E.; Aguila, C. Arch. Med. Vet.2001, 33, 21-29.

6. Tejada, C.; Quiñonez, E.; Peña, M. Rev. Fac. Ciencias Básicas 2014, 10, 80101.

7. Gogoi, A.; Mazumder, P.; Tyagi, V. K.; Tushara Chaminda, G. G.; An, A K.; Kumar, M. Groundw. Sustain. Dev.2018, 6, 169-180.

8. Zhang, Y.; Boyd, S. A.; Teppen, B. J.; Tiedje, J. M.; Li, H. Water Res. 2014, 65, 98-106.

9. Verma, A. K.; Dash, R. R.; Bhunia, P. J. Environ. Manage. 2012, 93, 154 168.

10. Aljerf, L. J. Urban Environ. Eng. 2018, 12, 50-58.

11. Huang, Y.; Feng, X. J. Membr. Sci. 2019, 586, 53-83.

12. Wang, Y.; Yao, M.; Chen, Y.; Zuo, Y.; Zhang, X.; Cui, L. J. Alloys Compd. 2015, 627, 7-12.

13. Zhang, Z.; Gao, P.; Cheng, J.; Liu, G.; Zhang, X.; Feng, Y. Water Res. 2018 , 136, 54-63.

14. Chen, Y. Y.; Ma, Y. L.; Yang, J.; Wang, L. Q.; Lv, J. M.; Ren, C. J. Chem. Eng. J. 2017, 307, 15-23.

15. Urbano, B. F.; Bustamante, S.; Palacio, D. A.; Vera, M.; Rivas, B. L. Polym. Int. 2020, 69, 333-345.

16. Chen, B.; Liu, Y.; Chen, S.; Zhao, X.; Meng, X.; Pan, X. J. Taiwan Inst. Chem. Eng. 2016, 67, 191-201.

17. Finlay, A. C.; Hobby, G. L.; P’An, S. Y.; Regna, P. P.; Routien, J. B.; Seeley, D. B.; Shull, G. M.; Sobin, B. A.; Solomons, I. A.; Vinson, J. W.; Kane, J. H. Science. 1950, 111, 85 .

18. Wright, C. S.; Tschan, D. N. A. M. A. Arch. Dermatology Syphilol. 1953, 67 125-128.

19. Francke, E. L.; Neu, H. C. Med. Clin. North Am. 1987, 71, 1155-1168

20. Florez, J.; Armijo, J. A.; Mediavilla, Á. Farmacología humana Florez, $3^{\circ}$ edicion; Manson, S. A.: Barcelona, España 1997.

21. Nelson, M. L. Tetracyclines Biol. Chem. Med. 2001, 1, 3-63.

22. Nelson, M. L. Adv. Dent. Res. 1998, 12, 5-11.

23. Pérez-Trallero, E.; Iglesias, L. Enferm. Infecc. Microbiol. Clin. 2003, 21 , 520-529.

24. Klein, N. C.; Cunha, B. A. Med. Clin. North Am. 1995, 79, 789-801.

25. Bel Prieto, E. Cienc. y Tecnol. Pharm. 2001, 11, 48-51.

26. Oka, H.; Ikai, Y.; Kawamura, N.; Yamada, M.; Harada, K. ichi; Ito, S.; Suzuki, M. J. Agric. Food Chem. 1989, 37, 226-231.

27. Loftin, K. A.; Adams, C. D.; Meyer, M. T.; Surampalli, R. J. Environ. Qual. 2008, 37, 378-386.

28. Ian, C.; Marilyn, R. Microbiol. Mol. Biol. Rev. 2001, 65, 232-260.

29. Dupuy, A. Farmacocinética de oxitetraciclina en dosificación oral múltiple en cerdos. Análisis PK-PD. Tesis doctoral, Universidad Complutense de Madrid: Madrid, España 2015. 
30. Stephens, C. R.; Murai, K.; Brunings, K. J.; Woodward, R. B. J. Am. Chem. Soc. 1 956, 78, 4155-4158.

31. Leeson, L. J.; Krueger, J. E.; Nash, R. A. J. New York 1963, 4155, 1155-1160.

32. Qiang, Z.; Adams, C. Water Res.2004, 38, 2874-2890.

33. Jones, A. D.; Bruland, G. L.; Agrawal, S. G.; Vasudevan, D. Environ. Toxicol. Chem. 2005, 24, 761-770.

34. Gonzales, P.A. Estudio de depleción de Oxitetraciclina en huevos obtenidos de gallinas de postura experimentales. Tesis pregrado, Universidad de Chile, Santiago, Chile 2013.

35. Tookwinas, S.; Keerativiriyaporn, S. Acquacult. Asia 2004, 9, 29-33.

36. Ferreira, C. S. G.; Nunes, B. A.; Henriques-Almeida, J. M. de M.; Guilhermino, L. Ecotoxicol. Environ. Saf.2007, 67, 452-458.

37. Burch, D. G. S. Examination of the pharmacokinetic/pharmacodynamic (PK/PD) relationships of orally administered antimicrobials and their correlation whit the therapy of various bacterial and mycoplasmal infections in pigs. Thesis for the Diploma of Fellowship, Royal College of Veterinary: London, England 2012.

38. Agwuh, K. N.; MacGowan, A. J. Antimicrob. Chemother. 2006, 58, 256-265.

39. Kolpin, D.; Furlong, E.; Zaugg, S.; Buxton, H. 2002, 36, 1999-2000.

40. Rodriguez-Narvaez, O. M.; Peralta-Hernandez, J. M.; Goonetilleke, A.; Bandala, E. R. Chem. Eng. J. 2017, 323, 361-380.

41. Pazda, M.; Kumirska, J.; Stepnowski, P.; Mulkiewicz, E. Sci. Total Environ.2019, 697, 134023.

42. Danalığlu, S. T.; Bayazit, Ş. S.; Kerkez, Ö.; Alhogbi, B. G.; Abdel Salam, M. Removal of ciprofloxacin from aqueous solution using humic acid-and levulinic acid-coated Fe3O4 nanoparticles. 2017, 123, 259-267.

43. Peng, X.; Hu, F.; Huang, J.; Wang, Y.; Dai, H.; Liu, Z. Microporous Mesoporous Mater.2016, 228, 196-206.

44. Pan, B.; Pan, B.; Zhang, W.; Lv, L.; Zhang, Q.; Zheng, S. Chem. Eng. J.2009, $151,19-29$.

45. Otero, M.; Zabkova, M.; Rodrigues, A. E. Sep. Purif. Technol. 2005, 45, 8695.

46. Lee, J. W.; Jung, H. J.; Kwak, D. H.; Chung, P. G. Water Res. 2005, 39, 617629.
47. Palacio, D. A.; Becerra, Y.; Urbano, B. F.; Rivas, B. L. Chemosphere 2020 , $258,127416$.

48. Tan, X.; Liu, Y.; Zeng, G.; Wang, X.; Hu, X.; Gu, Y.; Yang, Z. Chemosphere 2015, 125, 70-85.

49. Reyes B, H. Rev. Med. Chil. 2020, 148, 103-108.

50. Delgado, S. A.; Leyva, R. A.; Elizástegui, D. C.; Zerquera, H. A. Rev. Cuebana. Farm. 2009, 32, 164-168.

51. Choi, K.J.; Kim, S. G.; Kim, C. won; Kim, S. H. Chemosphere 2007, 66, $977-$ 984.

52. Choi, K. J.; Son, H. J.; Kim, S. H. Sci. Total Environ. 2007, 387, 247-256.

53. Wang, T.; Pan, X.; Ben, W.; Wang, J.; Hou, P.; Qiang, Z. J. Environ. Sci. (China) 2017, 52, 111-117.

54. Yang, W.; Zheng, F.; Lu, Y.; Xue, X.; Li, N. Ind. Eng. Chem. Res.2 011, 50, 13892.

55. Rivas, B.L.; Urbano, B. F.; Sánchez, J. Front. Chem. 2018, 6, 1-13.

56. Rivas, B.L.; Pereira, E.D.; Palencia, M.; Sánchez, J. Prog. Polym. Sci. 2011, 36, 294-322.

57. Palacio, D.A.; Rivas, B.L.; Urbano, B. F. Chem. Eng. J. 2018, 351, 85-93.

58. Palacio, D.A.; Leiton, L. M.; Urbano, B.F.; Rivas, B.L. Environ. Res. 2020, 182, 109014.

59. Rivas B.L,; Moreno-Villoslada I.; J. Membr. Sci. 2000, 178, 165-170.

60. Geckeler K.E.; Zhou R.N.; Rivas B.L. Angew. Makromol. Chem. 1992, 197, 107-115.

61. Rivas B.L.; Pooley S.A.; Luna M. Makromol. Rapid Commun. 2000, 21, $905-$ 908.

62. Rodríguez-Dorado, R.; Carro, A. M.; Chianella, I.; Karim, K.; Concheiro, A.; Lorenzo, R. A.; Piletsky, S.; Alvarez-Lorenzo, C. Anal. Bioanal. Chem. 2016, 408, 6845-6856.

63. Lu, Y.; Lei, L.; He, J.; Zhao, T. J. Sep. Sci.2020, 43, 2172-2179.

64. Aguilar, J. F. F.; Miranda, J. M.; Rodriguez, J. A.; Paez-Hernandez, M. E.; Ibarra, I. S. J. Polym. Res. 2020, 27, 1-12. 